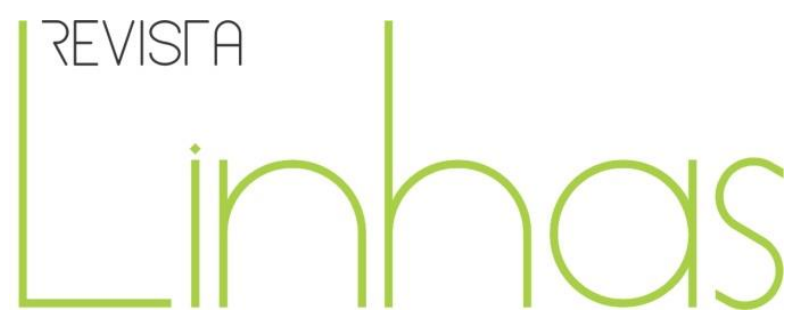

\title{
O processo de autoavaliação dos professores da educação infantil sobre educação de gênero: uma pesquisa em contextos italianos e brasileiros
}

\begin{abstract}
Resumo
Este artigo discute a autoavaliação dos professores de educação infantil quanto à educação de gênero implícita nas práticas pedagógicas. Durante os anos do programa de doutorado, trabalhei com grupos de professores com um método reflexivo, dialogando sobre contextos, para ter ideias mais explícitas sobre educação de gênero. Vou apresentar e descrever o processo de co-construção de uma escala de autoavaliação sobre educação de gênero: isso ocorreu em duas escolas infantis italianas estatais, em Palermo e, em uma escola infantil municipal brasileira, em Curitiba. A pesquisa apresentada refere-se às áreas de relações educacionais, linguagem, jogo simbólico, habilidade motora, socialização e relações entre adultos. Do ponto de vista da igualdade de oportunidades e da consciência da co-responsabilidade educacional entre a escola e as famílias, as escolas devem oferecer às crianças, sejam elas meninos ou meninas, as mesmas possibilidades para um desenvolvimento psicopedagógico harmonioso e completo, facilitando a socialização dentro do grupo de pares e promovendo potenciais individuais. Refletindo através do processo de autoavaliação no nível da escola de educação infantil, a partir de uma observação sistemática dos contextos escolares, pode-se perceber a ocorrência de estereótipos e preconceitos de gênero, através das discussões em equipe em um diálogo intersubjetivo, levando a uma melhoria da conscientização do professor e no ajuste das práticas educacionais.
\end{abstract}

Palavras-chave: Autoavaliação. Professores. Educação Infantil. Gênero. Conscientização.

\author{
Vittoria Castagna \\ Università degli Studi di Palermo - \\ Italia \\ vittoriacastagna@hotmail.com
}

\begin{abstract}
Para citar este artigo:
CASTAGNA, Vittoria. O processo de autoavaliação dos professores da educação infantil sobre educação de gênero: uma pesquisa em contextos italianos e brasileiros. Revista Linhas. Florianópolis, v. 19, n. 40, p. 246269, maio/ago. 2018. Título original: L'autovalutazione degli insegnanti di scuola dell'infanzia per un'educazione di genere: una ricerca pedagogica in contesti italiani e brasiliani. Traduzido por Fernando Coelho, com revisão técnica de Catarina Moro.
\end{abstract}

DOI: 10.5965/1984723819402018246

http://dx.doi.org/10.5965/1984723819402018246 


\title{
The kindergarten's teachers' self- evaluation process about gender education: a pedagogical research in certain Italian and Brazilian contexts
}

\begin{abstract}
This article discusses the self-evaluation of kindergarten teachers regarding the gender education implicit in educational practices. During the years of the PhD program, I worked with groups of teachers with a reflexive method, to dialogue about contexts to make more explicit ideas about gender education. I will present and describe the process of coconstruction of a self evaluation scale about gender education: this took place in two state-run Italian kindergartens in Palermo, and in a municipal Brazilian kindergarten in Curitiba. The presented research concerns the areas of educational relationships, language, symbolic play, motor ability, socialization and relations between adults. From an equal opportunities perspective and awareness of educational co-responsibility between school and families, schools should offer children, whether male and female, the same possibilities for a harmonious and all-round psycho-physical development, facilitating socialization within the peer group, and promoting individual potentials. Reflecting through the process of self-evaluation at the kindergarten level, starting from a systematic observation of schooling contexts, can allow gender stereotypes and prejudices to emerge, through the staff-team discussions in an intersubjective dialogue, leading to an improvement in teacher awareness and on adjustment of educational practices.
\end{abstract}

Keywords: Self-Evaluation. Kindergarten Teachers. Gender. Awareness. 


\section{Introdução}

Na pré-escola, deve ser proposta uma educação de gênero mais consciente, para a promoção de iguais oportunidades educacionais entre meninos e meninas, para o respeito e a valorização das diferenças e dos potenciais individuais infantis. O período de três a seis anos (relativo à pré-escola italiana) é de fato uma idade particularmente significativa para o desenvolvimento global da pessoa, no entrelaçamento de suas habilidades cognitivas, afetivas e relacionais.

Durante a minha pesquisa de doutorado, trabalhei no tema da formação de docentes de educação infantil em relação às práticas de gênero: em particular, trabalhei com dois grupos de professores da pré-escola estadual em Palermo (Itália) dois percursos destinados a co-construir um instrumento de autoavaliação reflexiva para a educação de gênero, mas também para a aprendizagem de um modelo de construção de um instrumento de avaliação.

Depois de ter construído uma primeira versão do instrumento com as professoras em Palermo, submeti-a a um grupo de docentes de uma instituição de educação infantil de Curitiba, no estado do Paraná/Brasil, para que pudessem analisá-la e a avaliassem a partir da perspectiva deles. Ao mesmo grupo de professoras, ainda propus um questionário, que eu construí, sobre a percepção das diferenças de gênero.

O quadro de referência teórico consiste em parte pelo modelo de avaliação formativa desenvolvido pela Universidade de Pavia (Itália), aprofundado e experimentado no Brasil também; por outro lado, o trabalho faz parte de uma linha de pesquisa pedagógica sobre educação de gênero, em particular italiana, com foco no debate internacional (principalmente europeu e brasileiro).

O instrumento co-construído visa favorecer o diálogo entre os grupos de docentes sobre as práticas educativas em relação ao gênero e para tornar explícitas, a partir da observação do contexto, ideias e concepções educacionais implícitas. 


\section{Para uma educação de gênero mais consciente na pré-escola}

O conceito de gênero diz respeito às conotações sócio-psico-culturais do ser biologicamente sexual (SARACENO, 1996).

Em todas as sociedades, os modelos de gênero determinam normas e formas nas quais o sujeito se identifica e representam referências implícitas na formação de sua própria identidade.

Por conseguinte, seria apropriado que a sociedade ofereça aos meninos e às meninas uma pluralidade de modelos de gênero, para que possam realizar o mais serenamente possível os processos de identificação e individuação, e se expressarem com maior liberdade. Sabemos que existem preconceitos discriminatórios e violência de gênero, e são mais ou menos explícitos, a partir de contextos familiares e educacionais, para assuntos considerados divergentes de um modelo de machismo tradicionalmente dominante e normativo. Sobre a oposição binária de gênero, forçada e implicitamente hierárquica, Lingiardi (2006, p. 15) escreve que

se pensarmos sobre a forma como os processos de cisão informam as construções dominantes de gênero, não podemos negligenciar o que é dividido e depois reprimido ou dissociado, na tentativa de adquirir identidades coerentes e culturalmente aprovadas, prolifera, diria Freud (1915a) na escuridão.

Mesmo a função reflexiva seria, portanto, empobrecida pela tentativa de aderir de maneira monolítica a um gênero normativo. No campo psicológico, destacou-se como a capacidade de um pai refletir sobre os estados mentais dos outros influencia muito o desenvolvimento da estrutura do Eu na criança (FONAGY; TARGET, 2001). A capacidade reflexiva pode ser adquirida através de um processo intersubjetivo, através de um processo de espelhamento ${ }^{1}$, no qual a criança aprende a reconhecer gradualmente emoções, sentimentos e pensamentos.

\footnotetext{
${ }^{1}$ Winnicott (1971, p. 184) liga a função de espelho da mãe, ou alguém com função materna, ao sentimento de "sentir-se real" da criança. Ele escreve: "Sentir-se real é mais do que existir; é encontrar uma maneira de
} 
O trabalho de desconstrução de estereótipos na educação de meninos e meninas pode nascer da consciência da disparidade de oportunidades educacionais para homens e mulheres, na história da educação até hoje. Vera Lucia de Oliveira Gomez (2005, p. 39), ao relatar o trabalho realizado com educadoras da primeira infância e crianças numa escola no Estado do Rio Grande do Sul, mostra como, além da aparente equidade no comportamento das professoras com meninos e meninas, por algumas declarações surgiram, durante a pesquisa, estereótipos tradicionalmente dominantes sobre homens e mulheres, que influenciam a construção da identidade de gênero no cotidiano: "Os meninos são mais agitados que as meninas, são menos tolerantes que as meninas. As meninas compreendem mais quando tu explica as coisas, os meninos não, né, tem que falar mais de uma vez porque eles querem usar a força". A autora então comenta que “Nesse processo, as diferencias socialmente construídas acabam sendo consideradas naturais e, como tal, inscritas no biológico e legitimadoras de uma relação de dominação."

Mesmo a partir da pré-escola, uma aparente neutralidade de gênero por parte do professor pode contribuir, involuntariamente, para a afirmação de processos de diferenciação alimentados na família, nos grupos de pares e pelos meios de comunicação de massa. Portanto, é necessária uma formação de professores que permita ler e contrabalançar o condicionamento do gênero e educar sobre a igualdade de oportunidades, em colaboração com as famílias. Uma formação inadequada pode implicar o risco de propor inconscientemente estereótipos e preconceitos de gênero: um modelo masculino de força poderosa e emocionalmente blindada e um modelo feminino baseado na docilidade e obediência. A segregação de gênero implica uma mutilação emocional e simbólica tradicionalmente imposta ao ser masculino ou feminino com características comportamentais pré-definidas como padrão de adequação masculina ou feminina, representa uma ilusão coerciva em relação à infinidade de declinação dos

existir como a si mesmo, e entrar em um relacionamento com objetos como a si mesmo, e ter um eu dentro do qual se recuar para relaxar.". Parece importante para mim enfatizar, portanto, que, de acordo com Winnicott, a capacidade de se sentir bem na solidão e a capacidade de interagir com os outros em um sentimento de reciprocidade, derivam da possibilidade de um relacionamento com um cuidador, "suficientemente bom", capaz de devolver à criança uma imagem de si mesmo, na autenticidade de emoções e pensamentos. 
modos, subjetivamente determinados, de ser e sentir-se como um homem, de ser e sentir-se como uma mulher. Essa dicotomização é o espelho de um modelo de sociedade adulta, funcional para a manutenção de uma dissimetria de oportunidades: por um lado é proposta $^{2}$ a imagem de um ideal masculino, forte, independente, blindado, agressivo; do outro lado, de um ideal feminino delicado, vaidoso, atencioso, cuidadoso.

Mesmo em atividades lúdicas, os estereótipos de gênero são muitas vezes propostos: se a brincadeira das meninas é frequentemente associada à esfera doméstica (espaço fechado e privado); a brincadeira dos meninos, pelo contrário, à exploração e aventura (espaço aberto e público).

A brincadeira simbólica é um dos meios expressivos e comunicativos preferidos na infância, e é caracterizado por aspectos de variedade, escolha e liberdade. Então, seria apropriado criar, na creche e na pré-escola, condições que incentivem uma ampla exploração lúdica e criativa, não correspondendo a estereótipos e oferecendo aos meninos e meninas diferentes modelos de gênero para se comparar.

Uma pesquisas recente ${ }^{3}$, promovida pela organização COFACE e pela União Europeia, foi realizada em nove países europeus, analisando a presença de estereótipos, raciais, de gênero e deficiência, em vários catálogos de brinquedos. Verificou-se que, na maioria dos catálogos examinados, imagens e mensagens estereotipadas estão presentes.

De acordo com Schreiber e Grauper (2017, p. 118), “É importante que se contemplem as discussões de gênero na Educação Infantil para que não seja reforçado um posicionamento que normatiza, disciplina e controla comportamentos infantis, reforçando estereótipos específicos para cada gênero." É muito importante que os serviços educacionais para a infância se caracterizem por um clima inclusivo, no qual as especificidades individuais sejam escutadas de forma enfática e valorizadas através da

\footnotetext{
${ }^{2}$ Em grande parte da literatura tradicional para a infância, são propostos estereótipos de gênero para homens e mulheres. Nessas décadas, projetos editoriais interessantes mostraram uma nova sensibilidade e atenção ao tema da educação de gênero, além dos estereótipos e da educação inclusiva.

${ }^{3}$ COFACE (Confederation of Family Organizations in the European Union). Toys catalogues in Europe: making orf breaking stereotypes?. Disponível em: <http://www.coface-eu.org/wpcontent/uploads/2017/01/ToysAndDiversity-Publication.pdf>. Acesso em: 2017.
} 
mediação e da competência dos adultos. O processo de identificação infantil é um passo delicado no crescimento e se desenvolve particularmente durante o período em que começam a se reconhecer como pertencendo a um determinado gênero, por volta dos dois/três anos de idade, e nos anos seguintes.

Para Di Ceglie (2015, p. 54): “O processo de aquisição da identidade de gênero prossegue paralelamente ao surgimento de um senso estável de si”. Ele também acrescenta que a construção da identidade de gênero está, no entanto, relacionada com o desejo de reconhecimento e com

a admissão da dependência, do nosso modo de estar nas mãos e no olhar do outro, sem o reconhecimento do qual não teríamos existido e não podemos existir. É então uma questão de desenvolver novas visões e encontrar novas palavras para narrar a complexidade do fenômeno. (p. 81)

O diálogo entre pesquisa pedagógica e instituições é uma prioridade para a criação de uma educação democrática e de qualidade para todas e para todos.

Para dar um exemplo significativo no contexto brasileiro, a proposta curricular da Rede Municipal de Florianópolis (FLORIANÓPOLIS, 2015a, p. 68), em relação à Educação Infantil, indica a importância de "[...] proporcionar brincadeiras diversas e jogos, através da organização do espaço, de brinquedos, de objetos e enredos, de modo que meninos e meninas tenham possibilidade de experimentar diferentes brincadeiras, independentemente do sexo".

Embora hoje tenha sido feito algum progresso na legislação sobre igualdade de oportunidades, tanto a nível italiano como internacional, continua a haver uma “pedagogia latente" na escola (BECCHI, 1978), que transmite uma educação de gênero, respondendo frequentemente a estereótipos discriminatórios, desde a pré-escola.

Na Itália, uma lei escolar foi aprovada recentemente (Lei 107/2015), que inclui um parágrafo que prevê o ensino na escola da educação às diferenças, para a prevenção da 
violência sexual e de gênero ${ }^{4}$. Este parágrafo não faz mais do que reconhecer a nível nacional o que foi decidido ao longo dos anos, com o consentimento de todos os países, a nível europeu, através das Declarações e na sede internacional com os Documentos ${ }^{5}$.

A autoavaliação formativa dos professores da pré-escola, do ponto de vista reflexivo ${ }^{6}$, poderia ser uma estratégia valiosa para esclarecer a educação implícita de gênero. Seria possível dar palavra e forma às motivações subjacentes aos comportamentos dos professores, para que possam agir de forma mais consciente e, portanto, intencionalmente, encorajar o desenvolvimento global dos meninos e das meninas.

A complexidade e a delicadeza do processo de formação de identidade de gênero exigem, de fato, uma participação sinérgica dos adultos que cuidam dos meninos e das meninas, visando uma compreensão empática das características específicas das crianças e seu aprimoramento.

Os adultos precisam da discrição e do respeito que lhes permitam aproximar-se dos pequenos, na autenticidade e através de um diálogo feito não só de palavras, mas também de linguagem não verbal, construído através do encontro de olhares, tons de voz, gestos.

\footnotetext{
${ }^{4} \mathrm{Em}$ resposta a uma controvérsia levantada por um grupo conservador extremista da sociedade italiana, tanto o MIUR (Ministério da Instrução, da Universidade e da Pesquisa) como a AIP (Associação Italiana de Psicologia) manifestaram-se claramente a favor da educação de gênero mais consciente e livre de estereótipos. A AIP publicou um documento intitulado "Sulla rilevanza scientifica degli studi di genere e orientamento sessuale e sulla loro diffusione nei contesti scolastici italiani" (2015), reiterando como "A inclusão nos projetos didáticos-formativos de conteúdos sobre gênero e orientação sexual ajuda a esclarecer as dimensões constitutivas da sexualidade e da afetividade, favorecendo uma cultura das diferenças e do respeito pela pessoa humana em todas as suas dimensões". Disponível em: http://www.aipass.org/documenti\%2oufficiali.

${ }^{5}$ Uma importante etapa legislativa a nível internacional, em particular no que diz respeito à aquisição de direitos iguais de sexo e de gênero, tanto para a infância como para a idade adulta, é representada pela CEDAW (Convention of the Elimination of all Forms of Discrimination Against Women), elaborada pela Assembleia Geral das Nações Unidas e ratificada por 180 países. Além disso, em 2014, o UNICEF também publicou um documento para a eliminação da discriminação contra crianças e pais com base na orientação sexual ou na identidade de gênero, Eliminating discrimination against children and parents based on sexual orientation and/or gender identity (Unicef Position Statement n.9, novembro de 2014).

${ }^{6} \mathrm{O}$ modelo de avaliação reflexiva caracteriza-se por um paradigma ecológico, pelo qual a instituição educacional é vista como um sistema no qual todos os atores da escola (crianças, pais, professores, dirigentes escolares, funcionários da escola) estão envolvidos no processo educacional de aprendizagem, interdependente e em relação com o território.
} 
A relacionalidade inerente no estar-no-mundo envolve sensações, emoções, sentimentos vividos e imaginação, e deve ser cultivada, por aqueles que ensinam, graças a uma formação reflexiva permanente.

\section{Um modelo de autoavaliação reflexiva para professores}

A pedagogia abordou a necessidade de uma formação contínua para os professores de todos os níveis escolares, destacando que deveria ser orientada para o desenvolvimento das competências didáticas, cognitivas e relacionais e por competências reflexivas e metacognitivas, pelo sabe aprender a aprender. A prática educacional diária requer uma flexibilidade que permita uma modulação contínua das ações a serem realizadas para tornar a escola interessante, acolhedora e um local de encontro entre as diferenças individuais, para todos os meninos e todas as meninas e para suas famílias. Para este fim, não basta aplicar currículos e um "desenvolvimento dos programas" escolares em termos de conteúdo, como, infelizmente, acontece muitas vezes já da pré-escola, mas há uma melhoria no profissionalismo dos docentes, porque é fundamental a relação educacional e saber como dar voz aos meninos e meninas, e colaborar com as famílias, de forma democrática.

O modelo de avaliação formativa para os professores de pré-escola, desenvolvido pelo grupo de pesquisa de Pavia (Itália), coordenado à época por Egle Becchi, promove uma ideia de escola (BONDIOLI, 2008, p. 13) como

configuração educacional, isto é, como uma organização complexa, que não termina na soma das ações dos indivíduos, é inserida em um contexto mais amplo, a partir do qual recebemos solicitações e com as quais entra em relação, cujas tarefas, especificamente formativas, interessam não só a pequena comunidade infantil que está hospedada lá, mas os adultos também que, de diferentes maneiras, estão envolvidos nisso e que, refletindo sobre suas próprias "ações" a favor da infância, desenvolvem um conhecimento e uma cultura que se enriquecem através da socialização e da troca.

Em uma sociedade complexa e plural, a escola, já desde a pré-escola, não pode escapar da tarefa de reconhecer e valorizar as diferenças e mediar os conflitos, sendo um 
local de encontro, construção de conhecimento e possibilidades de crescimento, transformação pessoal e social. O mesmo processo de avaliação contextual é configurado como um processo reflexivo de “mediação simbólica” (BONDIOLI; FERRARI, 2004).

Com o termo "contexto", nos referimos a um conjunto complexo de aspectos materiais, humanos e simbólicos, portanto, ao ambiente físico e relacional, que inclui todos os atores da escola.

O foco da minha pesquisa sobre formação de docentes, destinado a melhorar o potencial individual de meninos e meninas, além da "prisão" dos estereótipos de gênero, parece estar, na minha opinião, em linha com a filosofia da autoavaliação reflexiva: a comparação entre os diferentes pontos de vista das professoras nos contextos escolares observados visa a explicitação da "pedagogia latente" em relação aos gêneros. Estas ideias e valores, sem saber, velados por preconceitos e estereótipos discriminatórios sobre a concepção de menino e menina, que dificultam ou até impedem a livre expressão das emoções e das preferências na brincadeira, restringem o desenvolvimento da linguagem verbal e não-verbal, e inibem a capacidade de socialização.

De acordo com o modelo de avaliação do contexto, de Pavia, a comparação entre diferentes pontos de vista sobre as realidades educacionais pode dar origem à construção de um pensamento compartilhado e democrático, no qual estão presentes a subjetividade e um desejo e capacidade de cooperação profissional.

A criação de pontes metafóricas na comunicação em um grupo é uma das especificidades daquele que, como especialista fora da equipe, facilita a comunicação em um processo de avaliação contextual reflexiva, favorecendo a transição do plano do vivido para a experiência. De fato, ressalta Mignosi (2004, p. 155)

em relação à experiência, tanto no campo da pedagogia como da psicologia, é destacado que esta não coincide com o mero 'vivido', mas toma forma quando o vivido se torna objeto de reflexão e o sujeito se apropria disso para entender o seu significado. Consequentemente, o fazer, o agir na ausência de uma reflexão não coincide com o experimentar: a experiência é 'pensar no que se faz' e usa a prática para aumentar o conhecimento. Na experiência existe o entrelaçamento e reorganização de conhecimentos anteriores enriquecidos, amplificados ou mais bem definidos e vivificados pelos atuais... 
O modelo de Pavia do "avaliar-restituir-refletir-inovar-avaliar" (BONDIOLI, FERRARI, 2004) afirma a "natureza de negociação, participativa” e 'plurivocal' da qualidade e o valor atribuído à intersubjetividade em todas as fases do processo de avaliação" (BONDIOLI, 2015; BRASIL, 2015; BONDIOLI; SAVIO, 2013); a avaliação reflexiva não propõe, portanto, uma adaptação a padrões de qualidade préestabelecidos, mas promove a participação e o confronto entre professores e educadores, como também de todos os atores do processo educacional (famílias, operadores, gestores administrativos, políticos, crianças e sociedade civil), de um ponto de vista democrático, com "finalidade de negociação" (BONDIOLI, 2015): a reflexão compartilhada - que ocorre em particular na fase de restituição e interpretação coletiva dos dados coletados através da observação - é útil não só para explicar ideias pedagógicas e modelos implícitos nas práticas educativas, mas também para definir juntos uma ideia situada de "qualidade" e, consequentemente, das ações e decisões de melhoria, em uma determinada escola, com determinadas crianças, em um determinado território. A este respeito, estamos falando de "avaliar para $\operatorname{projetar}^{8 \% "}($ SAVIO, 2011, p. 56).

\footnotetext{
7 A avaliação do contexto é de natureza participativa: os professores participantes da pesquisa colaboram ativamente, participam ativamente como sujeitos do processo de avaliação, através do uso individual dos instrumentos de coleta de dados e da comparação intersubjetiva em equipe. É muito importante que um clima de não julgamento seja favorecido no grupo de trabalho, o que permite o surgimento de pontos de vista e diálogo. "Participação é algo concreto que vai além da intenção de se constituir como" um direito "ou um" dever "- é um compromisso entre as pessoas", de um grupo de pessoas determinado em um momento específico de uma escola particular (BONDIOLI, SAVIO 2013, p. 41). O recente documento brasileiro "Contribucoes para a politica nacional - A Avaliação em Educação Infantil à partir da Avaliação de Contexto" enfatiza que a participação é "condição e possibilidade de uma reflexão mais ampla sobre as experiências comuns" (BRASIL, 2015, p. 30), e como a avaliação deve ser incluída nos cursos de instituições educacionais, pois oferece uma preciosa oportunidade para "aumentar a conscientização e as possibilidades de reestruturação com base no próprio fazer" (p. 33); e também reitera que "a avaliação e a reflexão sobre a qualidade escolástica são processos intrinsecamente ligados e convergentes" (p. 33). Aqueles que promovem processos avaliativos "de dentro", um especialista fora do contexto escolar, garantidor do processo e de sua democracia, devem conhecer bem a filosofia de avaliação e os instrumentos, e poder esclarecer os valores expressos, encorajar a reflexão e facilitar a comunicação dentro do grupo, ao mesmo tempo em que se apresenta como ator no processo, participa como sujeito na dinâmica dialógica.
}

8 Nota Técnica da revisora: "projetar" não é um termo habitual na área da Educação no Brasil, mas na Itália é muito usual - progettare, progettazione, progettuale, progetto - e guarda o sentido de um planejamento flexível, aberto às observações e escutas sobre a dinâmica do grupo de crianças, da turma, para uma revisão contínua. Uma proposição acerca do trabalho, ampliando para além do vivenciado com as crianças, ou seja, entre os educadores/professores e com os pais/familiares, sujeita a modificações durante seu processo de andamento, flexível e global, podendo sofrer alterações, crescer em diferentes direções em 
O modelo de avaliação apresentado leva em consideração os aspectos materiais, relacionais, simbólicos e organizacionais da escola (materiais disponíveis, espaços, rotinas, atividades lúdicas e criativas, relacionamentos educacionais, relações entre colegas e famílias, etc.) e não tem a pretensão de ser exaustivo, considerando, aliás, a avaliação com um processo aberto.

Savio ressalta a necessidade de uma perspectiva "de baixo para cima", que busca responder à pergunta "como uma criança se sente neste ambiente?" (SAVIO, 2013, p. 224) com vista à uma educação inclusiva e democrática, capaz de melhorar as diferenças e especificidades individuais de todos os meninos e todas as meninas.

O modelo de qualidade escolar que foi delineado nestes anos é dinâmico, visando à transformação, à melhoria do sistema de serviços educacionais e à sua adaptação às necessidades educacionais daqueles que deles se utilizam. O conceito de negociação e participação da avaliação implica que a ideia de qualidade é construída de forma intersubjetiva, através do diálogo intersubjetivo e da narração de experiências a partir do próprio ponto de vista.

No recente relatório intitulado Un quadro europeo di qualità per i servizi educativi e di cura per l'infanzia: proposta di principi chiave, resultante da análise crítica do trabalho pela agência Eurydice, da OCDE, pela Rede Europeia da Infância e por outras organizações, no que diz respeito aos diferentes métodos de avaliação da qualidade, referindo-se ao período da educação infantil e caracterizados por uma abordagem inclusiva e colaborativa, são declarados alguns pressupostos fundamentais na educação: a necessidade de valorizar a imagem de uma criança como sujeito intencionalmente envolvido nos processos de aprendizagem e como sujeito de direitos ${ }^{9}$; a necessidade de participação e envolvimento das famílias; a necessidade de uma definição compartilhada de qualidade como um processo dinâmico, contínuo e

\footnotetext{
resposta às novas necessidadesque venham a ser identificadas, discutidas. Ver: RINALDI, Carla. Diálogos com Reggio Emilia: escutar, investigar e aprender. São Paulo: Paz e Terra, 2012.

9 Documento "Bambini in Europa" (2008), “L'infanzia e i servizi per l'infanzia: verso un approccio europeo". Disponível em: <www.grupponidiinfanzia.it/wp-content/uploads/2013/11/Linfanzia-e-i-servizi-per-linfanziaverso-un-approccio-europeo.pdf>. Acesso em: 2015.
} 
democrático, a ser implementado através de práticas de monitoramento e avaliação de contextos ${ }^{10}$.

Em relação ao contexto brasileiro, um documento de 2006, "Parâmetros Nacionais de Qualidade para Educação Infantil”, foi traduzido e detalhado em um instrumento de autoavaliação, "Indicadores da qualidade na educação infantil", publicado em 2009 pelo MEC (Ministério da Educação). Este último destinou-se a coordenadores, funcionários administrativos, professores e famílias, para refletir de forma participativa sobre os indicadores propostos, para a melhoria das práticas educativas, nele se estabelece um conceito de qualidade negociada, com base em direitos, necessidades e possibilidades de todas as unidades educacionais, para uma sociedade mais democrática, pacífica e solidária, em consonância com os princípios expressos na Constituição Federal e no Estatuto da Criança e Adolescente (ECA), entre os quais o "reconhecimento e valorização das diferenças de gênero, étnico-racial, religioso, cultural e relacionado às pessoas com deficiência" (Brasil, 2009, p. 12).

É em 20113, que O MEC reuniu um grupo de trabalho para contribuir com a definição de políticas de avaliação dos serviços educacionais: o trabalho produziu a publicação do documento "Política de Educação Infantil no Brasil: Relatório de Avaliação", que estabelece a necessidade de uma avaliação participativa e democrática e de uma colaboração entre escolas, universidades, instituições de pesquisa e associações na elaboração e promoção da pesquisa educacional. Em 2013, foi criada uma "Comissão de Especialistas em Educação Infantil", com a coordenação da Diretoria de Avaliação da Educação Básica (DAEB), para implementar a avaliação da educação infantil brasileira pelo INEP (Instituto Nacional de Estudos e Pesquisas Pedagógicas), que criou o grupo de trabalho para a avaliação da educação infantil.

\footnotetext{
${ }^{10}$ Afirma-se que as crianças são "colocadas no centro dos processos educacionais e de cuidados criados e atuados dentro dos serviços" e são caracterizadas pela sua singularidade e, individualmente, apresentam "necessidades diversificadas em termos de desenvolvimento emocional, motor, social e cognitivo, que, como tais, devem ser aceitas e reconhecidas." (LAZZARI, 2016, p.22-23). É declarada a necessidade de serviços "que encorajam a participação, o fortalecimento da inclusão social e o acolhimento da diversidade" e que o currículo deve "exigir que os operadores colaborem com colegas, crianças, pais e reflitam sobre as práticas atuadas", para um "experimento educacional ascendente que contribua para tornar sustentável a mudança dentro dos serviços” (p. 46-48).
} 
O atual Plano Nacional de Educação (PNE), 2014-2024, também explica os desafios relacionados à questão da avaliação e qualidade, declarando estratégias específicas, incluindo a realização bienal da avaliação participativa, com base em parâmetros nacionais de qualidade, com objetivo de criar um sistema de monitoramento e suporte para melhorar a qualidade dos serviços educacionais. No Brasil, são ativos fóruns de pesquisa que contribuem para a discussão pedagógica sobre a qualidade dos serviços para crianças, incentivando a participação social e o diálogo com as instituições, a nível local e nacional.

O documento DCNEI (Diretrizes Curriculares Nacionais para a Educação Infantil) de $2009^{11}$, explicita que a avaliação “do desenvolvimento das crianças" não tem objetivos de "seleção, promoção ou classificação" (art. 10, Brasil, 2009a, p. 5), mas de formação, e reitera os objetivos da educação em relação à infância, isto é, fomentar as diferentes linguagens expressivo-comunicativas e a socialização, respeitando o “direito à segurança, saúde, liberdade, confiança, respeito, dignidade, brincadeira, convivência e interação com outras crianças" (BRASIL, 2009a, p. 18).

Tanto o documento "Indicadores de qualidade na educação infantil" como o DCNEI, publicados em 2009, foram umas das fontes utilizadas para construir uma proposta para a elaboração ou revisão de instrumentos de avaliação na educação infantil, "Contribuições para a política nacional. Avaliação na educação infantil a partir da avaliação do contexto", foi publicado em 2015, pelo MEC, SEB (Secretaria de Educação Básica) e COEDI (Coordenação Geral de Educação Infantil), em colaboração com a UFPR (Universidade Federal do Paraná) com a coordenação de Rita de Cassia Freitas Coelho (Coordenadora Geral de Educação Infantil / COEDI / DICEI / SEB / MEC, e

\footnotetext{
${ }^{11}$ Enfatizo que, no documento, se declara que a Educação Infantil deve respeitar os "princípios éticos (autonomia, responsabilidade, solidariedade e respeito pelo bem comum, para o meio ambiente e para as diferentes culturas, identidades e singularidades), políticos (direitos de cidadania, ao exercício da capacidade crítica e ao respeito pela ordem democrática), estéticos (sensibilidade, criatividade, ludicidade, liberdade de expressão nas várias manifestações artísticas e culturais)" (Brasil, 2009, p. 16). Afirma-se que a proposta pedagógica das instituições deve oferecer - assegurando a participação, o diálogo e a escuta das famílias, no respeito e valorização das diversas formas de organização - condições e recursos para que as crianças se beneficiem dos direitos civis, humanos e sociais, em relação à democracia e com a libertação de relações de opressão geracional, socioeconômica, étnica-racial, de gênero e cultural. As DCNEI de 2009 também reconhecem a dignidade da criança como pessoa, proteção e prevenção contra qualquer forma de violência - física ou simbólica - e maus tratos na instituição ou atuada pelas famílias (Brasil, 2009, art. 8).
} 
de Gizele de Souza, Catarina Moro e Angela Scalabrin Coutinho (UFPR, Setor de Educação).

As "Contribuições para a política nacional" são caracterizadas por uma abordagem reflexiva, participativa e democrática para a avaliação do contexto em suas dimensões organizacionais (temporal, espacial, material, relacional), atenta à inclusão de diferenças étnicas, culturais e de gênero, para "garantir a cada criança oportunidades adequadas para o seu desenvolvimento, crescimento e aprendizagem" (BRASIL, 2015, p. 64).

Finalmente, gostaria de salientar que foram publicadas, em 2013, as “Diretrizes curriculares nacionais da educação básica”, que incluem a educação infantil. Na introdução dela, afirma-se que "A educação deve promover o desenvolvimento em sua plenitude, em condições de liberdade e dignidade, respeitando e valorizando as diferenças" (BRASIL, 2013, p. 4), no texto, afirma-se "em harmonia com os movimentos nacionais e internacionais um novo paradigma sobre os serviços para a infância", iniciado em 1959 com a Declaração Internacional dos Direitos da Infância e da Adolescência e se tornou uma referência para os movimentos sociais para o direito à educação infantil: nas DCNEB de 2013, um capítulo é dedicado à educação para os Direitos Humanos ${ }^{12}$, que para a sua realização e consolidação - é declarado - requer a participação e cooperação de uma grande variedade de assuntos e instituições:

todos os atores da educação devem participar do processo de implementação da Educação em Direitos Humanos. Isso significa que todas as pessoas, independentemente do seu gênero, origem nacional ou étnica, suas condições econômicas, sociais ou culturais, suas escolhas religiosas, orientação sexual, identidade de gênero, idade, deficiência ou alta habilidade, distúrbios do desenvolvimento, têm a oportunidade de aproveitar uma educação não discriminatória e democrática. (BRASIL, 2013, p. 516)

12 MINISTÉRIO DA EDUCAÇÃO CONSELHO NACIONAL DE EDUCAÇÃO CONSELHO PLENO, RESOLUÇÃO N 1 , DE 30 DE MAIO DE $2012(*)$ Estabelece Diretrizes Nacionais para a Educação em Direitos Humanos http://portal.mec.gov.br/index.php?option=com_docman\&view=download\&alias=10889-rcpoo1-

12\&category_slug=maio-2012-pdf\&ltemid=30192. No documento se declara que "todas as pessoas, independente do seu sexo; origem nacional, étnico-racial, de suas condições econômicas, sociais ou culturais; de suas escolhas de credo; orientação sexual; identidade de gênero, faixa etária, pessoas com deficiência, altas habilidades/superdotação, transtornos globais e do desenvolvimento, têm a possibilidade de usufruírem de uma educação não discriminatória e democrática." (BRASIL, 2013, p. 516). 


\section{O trabalho de construção do instrumento de autoavaliação para educação de gênero}

É neste quadro que meu trabalho de pesquisa está focado na autoavaliação reflexiva com professores de pré-escola para educação de gênero para melhorar as práticas educacionais.

Enquanto eu trabalhava em escolas em Palermo ${ }^{13}$, realizei cursos de observação e autoavaliação para a construção de uma ferramenta de autoavaliação para educação de gênero para professoras de pré-escola, além de aprender um modelo para a construção de um instrumento de avaliação da qualidade da pré-escola.

A parte experimental da minha pesquisa foi acompanhada pela elaboração, por minha parte, de relatórios narrativos como "instrumentação narrativa, dialógica, cronológica e reconstrutiva, útil tanto na fase de coleta de dados quanto na fase reflexiva" (BENVENUTO, 2015, p. 233).

A proposta dos percursos de autoavaliação com as professoras foi estruturada em diferentes fases: observação sistemática dos contextos educativos (ambientais e relacionais); uso individual de instrumentos de autoavaliação (coleta de dados); restituição pela pesquisadora dos dados coletados; confronto e diálogo sobre os dados coletados, a partir dos diferentes pontos de vista; co-construção de uma ferramenta de autoavaliação relacionada à educação para diferenças de gênero

As ferramentas utilizadas na pesquisa são duas escalas de observação e avaliação do contexto escolar - AVSI (Autoavaliação da Pré-escola) construída por um grupo de pesquisa pertencente à Universidade de Pavia e a ECERS-SOVASI (Escala de Observação e Autoavaliação da Pré-escola), construída na década de oitenta no contexto dos EUA, depois traduzida e adaptada em italiano pela equipe de pesquisa de Pavia - e um questionário de resposta mista sobre educação de gênero e questionários metaavaliativos, com abordagem de pesquisa qualitativa e participada.

\footnotetext{
${ }^{13} \mathrm{Em}$ uma primeira escola, o percurso teve lugar no bairro de Zisa, de maio de 2015 a fevereiro de 2016; na segunda, no bairro de Passo di Rigano-Auditore, de março a junho de 2016; um grupo de cinco e um grupo de sete professores estavam envolvidos e interessados em participar da pesquisa.
} 
As principais áreas de investigação diziam respeito à relação educacional, à responsabilização social das crianças, à consciência das diferenças, atividades lúdicascriativas, linguagem, socialização entre pares.

Após uma apresentação inicial às professoras do percurso e dos instrumentos utilizados para a pesquisa, propus o uso de um brainstorming de grupo sobre a educação de gênero, o que permitiu o surgimento e um primeiro compartilhamento de ideias relacionadas a possíveis diferenças entre meninos e meninas. Posteriormente, foi realizado o trabalho de observação e autoavaliação reflexiva, pelas professoras e por mim, como especialista em avaliação. Para a pesquisa, usei alguns indicadores ${ }^{14}$ das escalas de avaliação AVSI e SOVASI que propõem, entre os critérios de qualidade, também a sensibilização para as diferenças e a valorização das especificidades infantis individuais. Embora não construídos para a educação de gênero, são instrumentos caracterizados por uma articulação que permite ler a complexidade da experiência educacional e explicitar seus aspectos significativos. Posteriormente, dei um questionário com respostas abertas ${ }^{15}$ para investigar as diferentes percepções e representações sobre as diferenças de gênero entre meninos e meninas pelas professoras, com base na experiência profissional delas. A partir dos dados coletados e o confronto em grupo com as professoras, construí um instrumento de autoavaliação sobre educação de gênero, dividido em seis áreas: relação educativa, linguagem verbal, brincadeira simbólica, atividade motora, socialização entre pares, relações entre adultos (com especial referência ao clima relacional entre colegas de trabalho e colaboração entre escola e famílias).

\footnotetext{
${ }^{14} \mathrm{Em}$ particular, selecionei, de acordo com as professoras, os seguintes itens, porque foram considerados mais úteis para iniciar uma discussão sobre as práticas diárias de educação de gênero:

- AVSI: item 1 (inserção); item 3 (relações adulto-crianças); item 4 (responsabilização social das crianças); item 5 (organização dos grupos); item 6 (sensibilização às diferenças); item 20 (brincadeira do fingimento: materiais e preparação ambiental); item 22 (a brincadeira do fingimento: o papel do adulto).

- SOVASI: item 1 (vinda e despedida); item 5 (limpeza pessoal); item 13 (conceituação); item 14 (linguagem espontânea); item 21 (atividades artísticas); item 22 (música e dança); item 23 (construções); item 29 (brincadeira livre); item 31 (conscientização das especificidades); item 32 (clima social).

${ }^{15}$ Por exemplo, uma pergunta do questionário que eu criei é "Você acha que se comporta de maneira diferente com meninos e meninas na escola? Se sim, por quê? Em quais áreas?".
} 
A primeira versão do instrumento foi então discutida com os grupos de docentes das duas escolas de Palermo; através do uso de um questionário de meta-avaliação desenvolvido no percurso e um questionário sobre o instrumento realizado ${ }^{16}$, eu coletei ideias e sugestões para fazer mudanças e melhorias.

Em uma fase posterior ${ }^{17}$, passei um período de pesquisa em uma instituição de educação infantil no Brasil, da rede municipal na cidade de Curitiba. O percurso envolveu dez professoras da pré-escola, disponíveis e interessadas em participar do tema da educação de gênero. Inicialmente realizei uma reunião de apresentação do trabalho de pesquisa e de um questionário que construí sobre a percepção de diferenças de gênero no comportamento de meninos e meninas de acordo com a experiência profissional do docente. Eu fiz seis dias de observação nas salas de aula, com o objetivo de observar práticas de educação de gênero e, finalmente, entreguei às professoras os dados coletados durante a observação, estimulando uma discussão e uma reflexão grupal sobre ideias e opiniões relacionadas ao tema do gênero na educação. Posteriormente, dei um questionário sobre a percepção de diferenças de gênero no comportamento de meninos e meninas e o questionário de avaliação do instrumento construído em Palermo.

Pelas professoras envolvidas em Curitiba, o instrumento construído em Palermo foi considerado interessante e de utilidade potencial também para uma leitura e reflexão sobre as práticas educativas em contextos brasileiros. De acordo com a filosofia do modelo de autoavaliação utilizado, surgiu a necessidade de favorecer, em uma colaboração sinérgica com as famílias, as características individuais de meninos e meninas, e também que, na presença de diferentes condições socioeconômicas e familiares, os mesmos direitos no campo educacional sejam garantidos.

\footnotetext{
${ }^{16} \mathrm{O}$ questionário perguntava, em particular, se as professoras estavam de acordo com a filosofia e a gradação do valor da ferramenta e se acreditavam que os indicadores poderiam ser modificados ou adicionados para uma análise das práticas de educação de gênero.

${ }^{17}$ Em particular, do mês de abril a junho de 2017.
} 


\section{Observações, reflexões, paralelos entre Palermo e Curitiba}

Tanto em Palermo como em Curitiba, se, por um lado, foi declarada a ausência de estereótipos e de discriminação nos contextos escolares de referência, por outro, afirmou-se a existência de uma diferença no comportamento de meninos e meninas que respondem a uma ideia de estereótipos masculinos e femininos e, portanto, também já hierarquizada implicitamente.

Observou-se, a partir das observações e do cotejamento, que algumas áreas de brincadeira foram organizadas de acordo com os estereótipos de gênero (por exemplo, com a preparação do lugar para brincar no "salão de beleza" e no lugar para brincar na “oficina mecânica”) e que, embora não visassem exclusivamente a meninas ou meninos, essas áreas eram frequentemente frequentadas de maneira diferenciadas por gênero.

Durante os vários percursos de trabalho, tanto em Palermo quanto em Curitiba, emergiram, através do uso dos instrumentos, algumas ideias semelhantes de menina e menino e alguns modelos de gênero implícitos em práticas educativas.

Em particular, através dos dados encontrados em Palermo e Curitiba, a respeito da esfera expressiva e comunicativa, surgiu a ideia de que as meninas sejam mais afetuosas e expansivas, externem mais suas emoções, "usem" o choro, sejam mais maduras na expressão linguística e que os meninos expressem mais a oposição e raiva, e tenham maior dificuldade na linguagem verbal. No que diz respeito à área lúdico-criativa ${ }^{18}$, algumas professoras declararam que não há diferenças no comportamento de meninos e meninas, e as preferências e modalidades da brincadeira e a expressão criativa dependem do sujeito; outras professoras expressaram a ideia de que "na maioria dos casos" há diferenças no comportamento lúdico de meninos e meninas. Por exemplo, afirmou-se que os meninos prefeririam a brincadeira livre, jogos de construção, máquinas, "transformers", animais, competições de luta, personagens de super-heróis e atividades de movimento, e que eles seriam mais impetuosos e/ou mais engraçados na brincadeira motora, enquanto as meninas estariam mais orientadas para a brincadeira de papéis e

\footnotetext{
${ }^{18}$ Certamente, as áreas investigadas estão intimamente interligadas. Por exemplo, a brincadeira também é um meio de expressão e comunicação.
} 
simbólica (por exemplo, de acordo com algumas professoras, as meninas preferem papéis familiares, em particular, brincando para representar a mãe, a professora, a esteticista...), prefeririam brinquedos como louça, bonecas, adorariam brincadeiras mais silenciosas das que dos meninos, e a dança. Ao mesmo tempo, tanto em Palermo como em Curitiba, destacou-se a ideia de que os meninos e as meninas socializam diariamente entre eles, tanto durante as atividades lúdicas (brincadeira motora, simbólica, atividade criativo-manipuladora, quebra-cabeças, jogos de tabuleiro, etc.), quanto durante as rotinas (por exemplo, o almoço) e momentos de transição (por exemplo, em momentos de espera entre uma atividade educacional e outra).

No entanto, as docentes expressaram diferentes pontos de vista e ideias, que foram, nas escolas, em Palermo e Curitiba, motivo de diálogo e explicitação dos modelos tacitamente expressos nas práticas, tanto no que se refere aos aspectos relacionais (relacionamento educacional, relações entre pares, relações entre escola e famílias) que materiais ${ }^{19}$ (por exemplo, a preparação das salas de aula, brinquedos e livros utilizados).

Embora tenha ficado claro que os aspectos materiais estão determinados culturalmente, demorou mais tempo para alguns professores a aceitar a ideia de que os aspectos relacionais e simbólicos também são influenciados por fatores sociais. Por exemplo, em Palermo, algumas professoras inicialmente enfatizaram um caráter "espontâneo" da relação educativa, o que dificultaria a possibilidade de aprender a respeito e de uma formação docente exatamente nos aspectos relacionais.

Além disso, embora os fatores que afetam a educação de gênero tenham sido comumente reconhecidos pela sociedade e pelas famílias, em algumas participantes faltou a expressão de uma consciência do papel da escola no fortalecimento ou enfraquecimento dos estereótipos que continuam a alimentar disparidade de gênero.

Um exemplo de discriminação de gênero não mediada adequadamente pelas professoras é representada por esta situação de brincadeira entre meninos e meninas, que observei na escola brasileira:

\footnotetext{
${ }^{19}$ Destaco a trama indissolúvel entre aspectos relacionais e materiais.
} 
Dois meninos e uma menina brincam com as construções; um menino quer um pedaço das construções com o qual a menina está brincando; diz-lhe para dá-lo a ele e ir brincar com a cozinha. Ela joga no chão as peças com que ela estava brincando e diz, como se estivesse com resignação e raiva: "Eu vou brincar na cozinha!". Várias meninas estão brincando na cozinha, outras desenham. Os meninos brincam com construções e carros. Uma menina dorme em um canto para o descanso. Algumas meninas jogam com bonecas, dão comida ao bebê. Uma criança, que acabou de chegar na sala de aula, chora; a professora dirigeme a fala dizendo-me que ela se comporta assim "quando ela está descontente". Uma menina se aproxima dos dois meninos que estão brincando com as construções; o menino, que disse à sua coleguinha para brincar com a cozinha, também fala para essa menina que ela não pode brincar, ela pergunta o porquê, ele responde que ela tem que ir "para a cozinha". Ela pega algumas peças de construção, vem brincar ao meu lado e depois, eu diria com satisfação, ela me mostra o que ela construiu.

Esta descrição observacional de um momento da vida escolar diária parece-me destacar, em conclusão, a necessidade de ouvir e conscientizar o professor para que os estereótipos discriminatórios não sejam reproduzidos nas práticas educativas diárias e os direitos das crianças sejam tutelados.

Através da autoavaliação de contexto, o professor se torna um pesquisador, um sujeito ativo na pesquisa, em conhecer e analisar os contextos em que ele trabalha e de que faz parte; o trabalho em grupo baseia-se no reconhecimento das diferenças interpessoais, na audição, na mediação, no potencial transformador e melhorador do trabalho de observação dos contextos escolares e da interpretação compartilhada dos dados coletados. Não se trata de definir verdades “objetivas", mas de reconhecer a parcialidade dos pontos de vista sobre as práticas educativas e a importância do diálogo em conjunto, para a criação de melhores condições para o bem-estar psicofísico e para o crescimento global, mais harmonioso e mais pacífico, de meninos e meninas. 


\section{Referências}

Benvenuto Guido, Stili e metodi della ricerca educativa, Carocci, Roma, 2015.

Bondioli Anna, Savio Donatella, a cura di, La valutazione di contesto nei servizi per I'infanzia italiani, Edizioni Junior, Parma, 2015.

Bondioli Anna, Ferrari Monica, Ferrari Valerio, Mignosi Elena, Savio Donatella, Leggere le Indicazioni. Riflessioni e proposte per la scuola dell'infanzia, Edizioni Junior-Spaggiari, Parma, 2013.

Bondioli Anna, Ferrari Monica, a cura di, Educare la professionalità degli educatori per I'infanzia, Junior Editore, Bergamo, 2004.

Bondioli, Anna, Becchi Egle, Ferrari Monica, Gariboldi Antonio, Scala AVSI.

Autovalutazione nella scuola dell'infanzia, Franco Angeli, Milano, 2001.

Brasil, DCNEI, Diretrizes Curriculares Nacionais para a Educação Infantil Diario oficial da Uniao, Brasilia, DF, 18 dez. 2009².

Brasil, Indicadores da qualidade na Educação Infantil, Brasilia, DF: MEC/SEB/COEDI, 2009b.

Brasil, Parametros Nacionais de qualidade para a Educação Infantil, Brasilia, DF: $\mathrm{MEC} / \mathrm{SEB} / \mathrm{DPE} / \mathrm{COEDI} / 2006 \mathrm{~b}$.

Burgio Giuseppe, Il bambino e l'armatura. Maschilità, violenza, educazione in Ulivieri S., a cura di, Educazione al femminile. Una storia da scoprire, Guerini, Milano, 2007.

COFACE (Confederation of Family Organizations in the European Union), Toys catalogues in Europe: making or breaking stereotypes?, 2016.

http://www.coface-eu.org/wp-content/uploads/2017/01/ToysAndDiversity-Publication.pdf De Oliveira Gomes Vera Lucia, A CONSTRUÇÃO DO FEMININO E DO MASCULINO NO PROCESSO DE CUIDAR CRIANÇAS EM PRÉ-ESCOLAS, in Texto, contexto, enfermagem, Florianopolis, 2006, 15(1).

De Souza Gizele, Moro Catarina, Scalabrin Coutinho Angela, Formação da rede em educação infantil: avaliação de contexto, Appris Editora, Curitiba, 2015. Fonagy Peter, Target Mary, Mentalizzazione e attaccamento, Cortina Editore, Milano, 2001.

FLORIANÓPOLIS, Curriculo da Educação Infantil da Rede Municipal de Ensino de Florianopolis, 2015, Volume III. 
Fundação Carlo Chagas, Departamento de pesquisas educacionais, Consulta sobre qualidade de educação infantil, 2006.

<file:///C:/Users/Acer/Downloads/qualidade_educacao_infantil_brasil.pdf >.

Harms T., Clifford R.M., adattamento italiano di Monica Ferrari e Antonio Gariboldi, Sovasi, Scala di Osservazione e Valutazione della Scuola dell'Infanzia, Edizioni Junior, Azzano San Paolo (BG), 2003.

Lazzari Arianna, a cura di, Un quadro europeo per la qualità dei servizi educativi e di cura per l'infanzia: proposta di principi chiave. Rapporto elaborato dal Gruppo di Lavoro Tematico sull'Educazione e Cura dell'Infanzia sotto l'egida della Commissione Europea, Zeroseiup, San Paolo d'Argon (BG), 2016.

Lingiardi Vittorio, La generazione del soggetto in Dimen Muriel., Goldner Virginia., La decostruzione del genere, II Saggiatore, Milano, 2006.

MEC, Lei do PNE (Plano Nacional de Educação) n.13.005/2014

http://www.planalto.gov.br/CCIVIL_03/_Ato2011-2014/2014/Lei/L13005.htm

MEC/SEB/COEDI/UFPR, Contribuçoes-para-a-politica-nacional-a-avaliacao-em-educacaoinfantil-a-partir-da-avaliacao-de-contexto, Curitiba, PR, 2015.

MINISTÉRIO DA EDUCAÇÃO, CONSELHO NACIONAL DE EDUCAÇÃO, CONSELHO PLENO, RESOLUÇÃO N 1, DE 30 DE MAIO DE 2012 (*) Estabelece Diretrizes Nacionais para a Educação em Direitos Humanos

http://portal.mec.gov.br/index.php?option=com_docman\&view=download\&alias=10889rcpo01-12\&category_slug=maio-2012-pdf\&Itemid=30192

MIUR (Ministero dell'Istruzione, dell'Università e della Ricerca), Legge107/2015

http://www.gazzettaufficiale.it/eli/id/2015/07/15/15G00122/sg

http://www.istruzione.it/allegati/2015/prot1972.pdf

Mignosi Elena, Far crescere la professionalità: esperienze di formazione al "pensare riflessivo" in Bondioli A., Ferrari M., a cura di, Educare la professionalità degli operatori per l'infanzia, Edizioni Junior, 2004.

ONU, (1979), The Convention on the Elimination of All Forms of Discrimination against Women (CEDAW)

http://www.un.org/womenwatch/daw/cedaw/cedaw.htm

ONU, (1989), Convention on the Rights of the Child

http://www.ohchr.org/EN/Professionallnterest/Pages/CRC.aspx

Piccone Stella Simonetta, Saraceno Chiara, a cura di, Genere. La costruzione sociale del femminile e del maschile, II Mulino, Bologna, 1996. 
Quagliata Emanuela, Di Ceglie Domenico, Lo sviluppo dell'identità sessuale e l'identità di genere, Astrolabio-Ubaldini Editore, Roma, 2015.

Savio Donatella, Il gioco e l'identità educativa del nido d'infanzia, Edizioni Junior, Azzano San Paolo (BG), 2011.

Schreiber Elisabeth, Graupe Mareli Eliane., Gênero na Educação Infantil: análise dos planejamentos e do PPP de um núcleo de educação infantil de Florianópolis, in Revista Zeroa-seis, Jan./Jun. 2017.

UNICEF (2014), Eliminating discrimination against children and parents based on sexual orientation and/or gender identity, (Unicef Position Statement n.9)

http://www.unicef.it/Allegati/Position_Paper_Sexual_Identification_and_Gender_Identity _12_Nov_2014.pdf

Vianna Claudia, Finco Daniela, Meninas e meninos na Educação Infantil: uma questão de gênero e poder in Cadernos Pagu, julho-dezembro 2009.

Winnicott Donald, Gioco e realtà, Armando Editore, Roma, 2006 (Ed. originale 1971).

Recebido em: 20/02/2018 Aprovado em: 30/03/2018

Universidade do Estado de Santa Catarina - UDESC Programa de Pós-Graduação em Educação - PPGE Revista Linhas Volume 19 - Número 40 - Ano 2018 revistalinhas@gmail.com 